\title{
Versatile deprotonated NHC: C,N-bridged dinuclear iridium and rhodium complexes
}

\author{
Albert Poater
}

\author{
Full Research Paper \\ Address: \\ Institut de Química Computacional i Catàlisi, Departament de \\ Química, Universitat de Girona, Campus de Montilivi, E-17071 \\ Girona, Spain \\ Email: \\ Albert Poater - albert.poater@udg.edu \\ Keywords: \\ DFT; head-to-head; head-to-tail; iridium; isomerization; N-heterocyclic \\ carbene; rhodium \\ Beilstein J. Org. Chem. 2016, 12, 117-124. \\ doi:10.3762/bjoc. 12.13 \\ Received: 29 November 2015 \\ Accepted: 08 January 2016 \\ Published: 22 January 2016 \\ This article is part of the Thematic Series "N-Heterocyclic carbenes". \\ Guest Editor: S. P. Nolan \\ (c) 2016 Poater; licensee Beilstein-Institut. \\ License and terms: see end of document.
}

\begin{abstract}
Bearing the versatility of N-heterocyclic carbene (NHC) ligands, here density functional theory (DFT) calculations unravel the capacity of coordination of a deprotonated NHC ligand (pNHC) to generate a doubly C2,N3-bridged dinuclear complex. Here, in particular the discussion is based on the combination of the deprotonated 1-arylimidazol (aryl = mesityl $(\mathrm{Mes}))$ with $[\mathrm{M}(\mathrm{cod})(\mu-\mathrm{Cl})]$ $(\mathrm{M}=\mathrm{Ir}, \mathrm{Rh})$ generated two geometrical isomers of complex $\left.\left[\mathrm{M}(\operatorname{cod})\left\{\mu-\mathrm{C}_{3} \mathrm{H}_{2} \mathrm{~N}_{2}(\mathrm{Mes})-\kappa \mathrm{C} 2, \kappa N 3\right\}\right]_{2}\right)$. The latter two isomers display conformations head-to-head $(\mathrm{H}-\mathrm{H})$ and head-to-tail $(\mathrm{H}-\mathrm{T})$ of $C_{\mathrm{S}}$ and $C_{2}$ symmetry, respectively. The isomerization from the $\mathrm{H}-\mathrm{H}$ to the H-T conformation is feasible, whereas next substitutions of the cod ligand by $\mathrm{CO}$ first, and $\mathrm{PMe}_{3}$ later confirm the $\mathrm{H}-\mathrm{T}$ coordination as the thermodynamically preferred. It is envisaged the exchange of the metal, from iridium to rhodium, confirming here the innocence of the nature of the metal for such arrangements of the bridging ligands.
\end{abstract}

\section{Introduction}

In the framework of organometallic chemistry, N-heterocyclic carbenes (NHC) centre a well stablished class of relatively new ligands since in 1991 Arduengo and collaborators isolated the first stable NHC of the imidazole type with bulky N-substituents [1]. However the existence of stable NHCs was before postulated by Wanzlick et al. during the 1960s [2-4] and supported later by Öfele $[5,6]$. NHCs have become useful ligands in many transition metal-catalyzed reactions, stimulating the study of the unique features of the $\mathrm{M}-\mathrm{NHC}$ bond [7,8], which favored the synthesis of new NHCs and to their use as ligands in transition metal complexes. The latter complexes were usually obtained by an easy replacement of a phosphine by the new NHC ligand, displaying a very high stability under many catalytic conditions. Furthermore, NHCs exhibit better activity, despite bearing its carbene functionality. Of course, these good results in basic research supposed and explosion of industrial efforts to design the right metal NHC-based catalyst for any kind of reaction. Anyway, neither a unique nor a few list of 
catalysts turned out to be effective for any catalytic reaction, but some successful applications were achieved in the field of Ru-catalyzed metathesis of olefins [9-12], Ir-catalyzed hydrogenation $[13,14]$, Pd-catalyzed $\mathrm{C}=\mathrm{C}$ coupling reactions $[15,16]$, Ir-catalyzed $\mathrm{CO}_{2}$ fixation [17,18], and/or functionalization of alkenes and alkynes by Au-catalyzed reactions [19-21].

It is not feasible to exclude the asymmetry thanks to the modification of any of the two groups on the imidazolin-2-ylidene ring for two reasons. First, $\mathrm{H}$ atoms on the backbone of the either saturated or unsaturated imidazolin-2-ylidene ring suppose a key structural feature for the introduction of asymmetry in the NHC ring. Second, these $\mathrm{H}$ atoms might transform the corresponding NHCs in potentially efficient chiral NHCs in asymmetric synthesis [22]. Following with the latter recipe, protic NHCs (pNHCs) consist of the presence of a N-bound $\mathrm{H}$ atom. Although most of the studies on NHCs together with metal moieties are based on the interaction of the carbene carbon of the NHC with the metal [23-26], the high instability due the NH group of the pNHCs can induce secondary interactions leading to bifunctional catalysis [27,28], substrate recognition [29] and/ or biological systems [30,31]. Among the synthetic methodologies to access to pNHC metal complexes [32-40], recently $\mathrm{N}$-arylimine functionalized $\mathrm{pNHC}$ iridium complexes were obtained using excess of $[\operatorname{Ir}(\operatorname{cod})(\mu-\mathrm{Cl})]_{2}[41]$, and next deprotonation of the pNHC leads to an equilibrium between a mononuclear complex containing a C-bound anionic imidazolide [42$44]$ and its dimer [45-58], where the NHC moiety binds in a $\mu-\mathrm{C}, \mathrm{N}$ bridging mode (see Scheme 1) [44].

Even though during the last two decades thousands of papers have presented and described the NHC based catalysis, bearing a carbene-metal coordination [7], catalytically few efforts have been dedicated to other types of coordination of the NHC with the metal. Braunstein and collaborators have smartly faced the challenge to mix the reactivity of both coordinative atoms of pNHCs [59], either the carbene carbon or the non-substituted nitrogen, i.e., the $\mathrm{N}$ from the former $\mathrm{N}-\mathrm{H}$ group, bearing 1 -arylimidazolide ligands. Scheme 2 contains the general scheme that leads to a particular case of the "equilibrium" be-

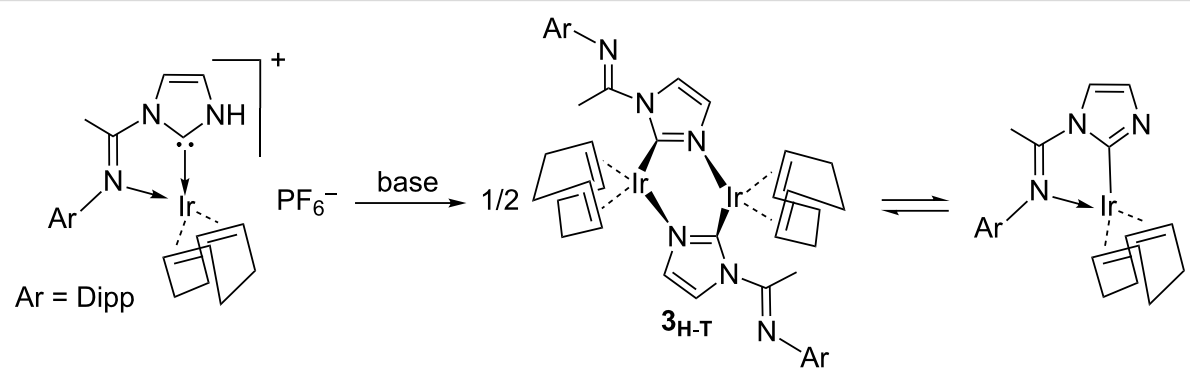

Scheme 1: Equilibrium between the monoiridum complex bearing a C-bound anionic imidazolide and its corresponding dimer, once deprotonated a pNHC.

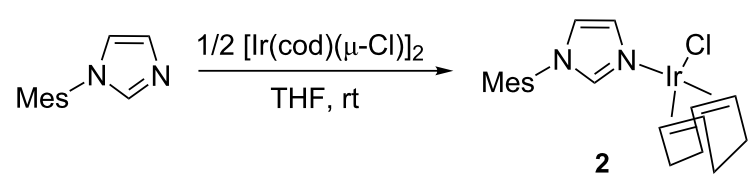

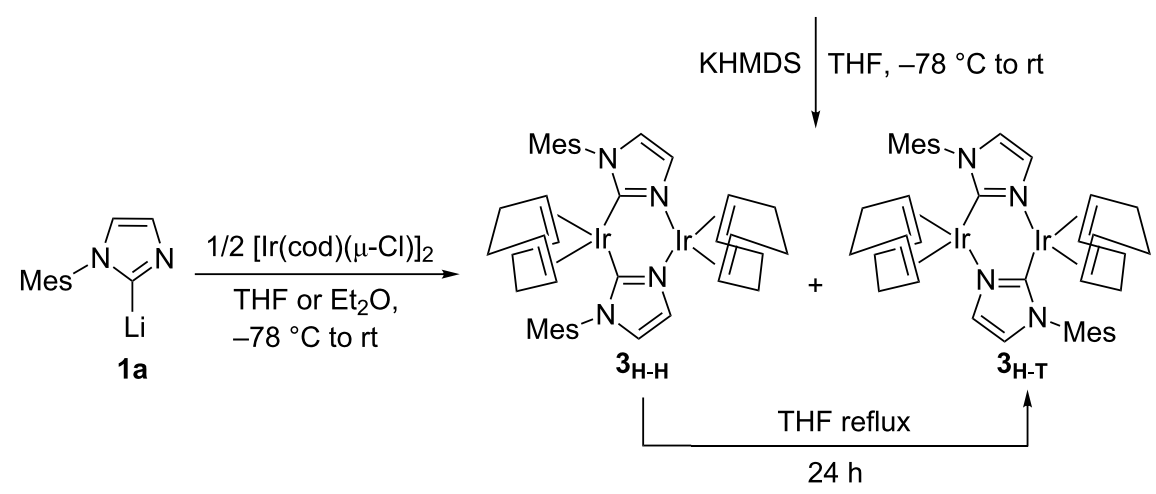

Scheme 2: Experimental routes to the "equilibrium" between $\mathbf{3}_{\mathrm{H}-\mathrm{H}}$ and $\mathbf{3}_{\mathrm{H}-\mathrm{T}}$. 
tween two dinuclear complexes, labelled $\mathbf{3}_{\mathbf{H}-\mathbf{H}}$ and $\mathbf{3}_{\mathbf{H}-\mathbf{T}}$ (where $\mathrm{H}-\mathrm{H}=$ head-to-head and $\mathrm{H}-\mathrm{T}$ = head-to-tail). By DFT calculations here we contribute in the understanding of the thermodynamics of the subsequent $\mathrm{C}, \mathrm{N}$-bridged dinuclear iridium and rhodium complexes [59], and the facility for the interconversion between these latter dimeric species.

\section{Results}

To shed light about both isomers of the dinuclear complex $\mathbf{3}$, $\mathbf{3}_{\mathbf{H}-\mathbf{H}}$ and $\mathbf{3}_{\mathbf{H}-\mathrm{T}}$, we envisaged DFT calculations (see Figure 1). The optimized geometry of $\mathbf{3}_{\mathbf{H}-\mathbf{H}}$ is in perfect agreement with the X-ray structure [60] ( $\mathrm{rmsd}=0.065 \AA$ and $1.1^{\circ}$ for the selected main distances and angles) $[61,62]$. In agreement with experiments that indicated $\mathbf{3}_{\mathbf{H}-\mathbf{T}}$ is $5.2 \mathrm{kcal} / \mathrm{mol}$ more stable than $\mathbf{3}_{\mathbf{H}-\mathbf{H}}$, which means that with free tautomerism only the thermodynamic isomer $\mathbf{3}_{\mathbf{H}-\mathbf{T}}$ would not coexist with $\mathbf{3}_{\mathbf{H}-\mathbf{H}}$, but as the unique isomer [59].

Furthermore, the strength of the two H-H and H-T arrangements of the bridging pNHC ligand with the iridium was examined with the Mayer bond order (MBO) [63], which is valuable for evaluating bonding in main group compounds, but has been also used as a tool for the characterization of transition metal systems $[64,65]$. For $\mathbf{3}_{\mathbf{H}-\mathbf{H}}$ the NHC coordination to the metal through the carbene carbon, the $\mathrm{MBO}$ is 0.874 , whereas through the $\mathrm{N}$ atom is only 0.438 . The type of coordination of pNHCs around the iridium atoms, either $\mathrm{H}-\mathrm{H}$ or $\mathrm{H}-\mathrm{T}$, does not modify significantly the strength of the Ir-C and Ir-N bonds. For $\mathbf{3}_{\mathbf{H}-\mathrm{T}}$ the MBO values are 0.841 and 0.410 . Further, the structure of the dinuclear complexes may be determined by steric effects of both monomeric moieties. To evaluate only the sterics, topo- graphic steric maps were used, which are calculated through the SambVca package developed by Cavallo et al. [66]. This analysis allows the rationalization of the first coordination sphere around metal centres where catalytic processes take place. Basically the method calculates the buried volume of a given ligand [67] based on the quantification of the proportion of the first coordination sphere of the metal occupied by this ligand. The encumbered zones (color-coded in brown) belong to the part of the ligand that protrudes in the direction of the reacting groups, thus restricting the space they can fill, whereas empty zones (color coded in blue) correspond to the part where the ligand retracts from the reacting groups $[68,69]$.

For $\mathbf{3}_{\mathbf{H}-\mathbf{H}}$ the percentage of buried volume (\%VBur) is 26.2 bearing a metal-carbene coordination, whereas it decreases to only 19.1 when the NHC bonds to the metal through the deprotonated nitrogen atom. However, the steric maps in Figure 2 confirm completely that the system prefers the latter N-bound coordination. Splitting the map into four quadrants the carbene coordination reveals a quadrant highly sterically hindered (37.2) due to the rotation of the aromatic ring on the NHC which facilitates the allocation of such a NHC ligand in the dinuclear complexes. The other quadrant where this aromatic ring participates displays a value of 29.2, whereas the other two are innocuous for the metal sphere with low values of 19.3 and 19.1. On the other hand, the coordination of the NHC through the nitrogen is sterically innocent towards the metal sphere because the four quadrants show low sterical occupations (19.1, 18.7, 19.4 and 19.1). Thus, the N-bound coordination of the NHC can be regarded as the perfect coordination to facilitate a free "first coordination sphere", with enough space for allowing the for- a)

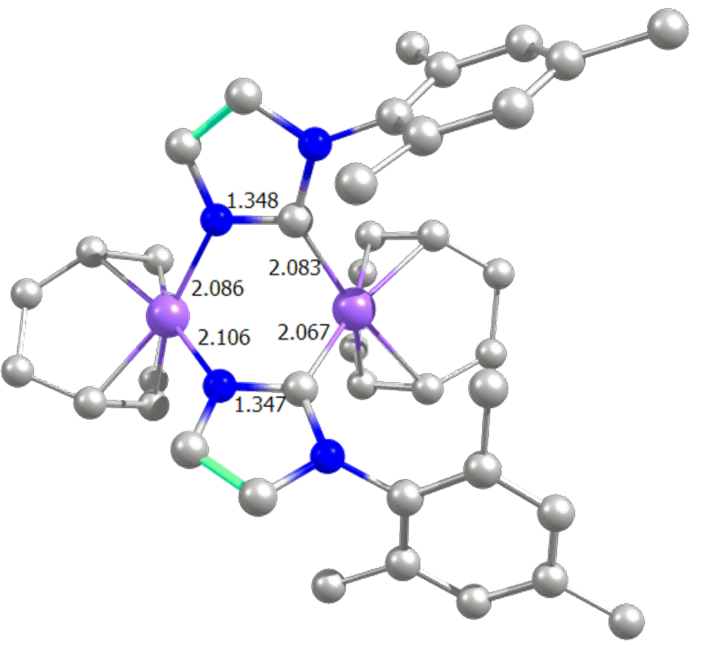

b)

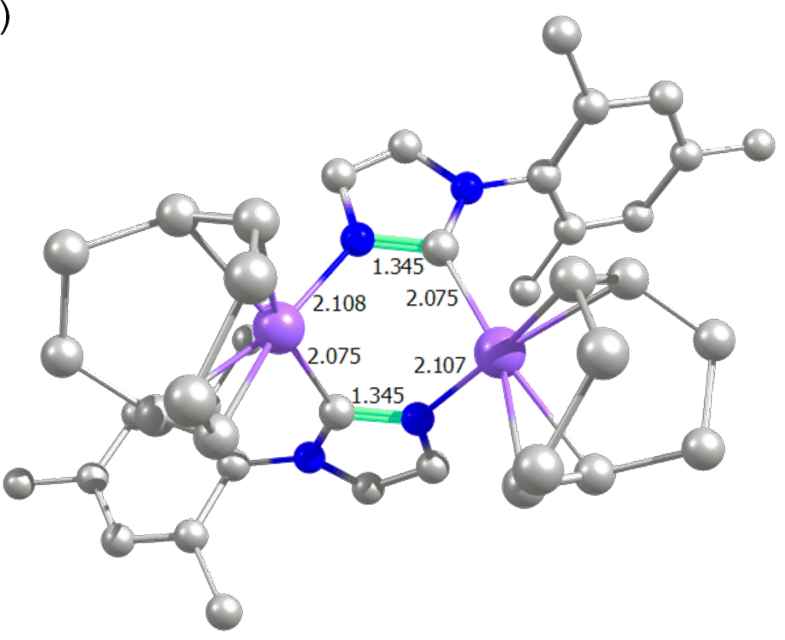

Figure 1: View of the molecular structure of a) $3_{\mathrm{H}-\mathrm{H}}$ and b) $\mathbf{3}_{\mathrm{H}-\mathrm{T}}$. Hydrogen atoms have been omitted for the sake of clarity (main distances in $\AA$ ). 
a)

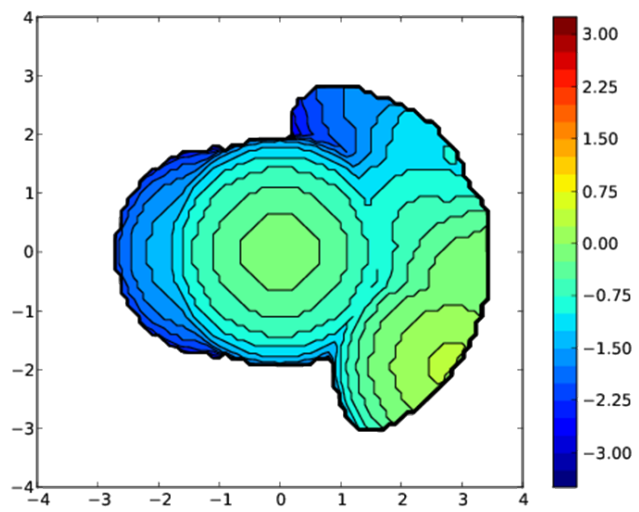

b)

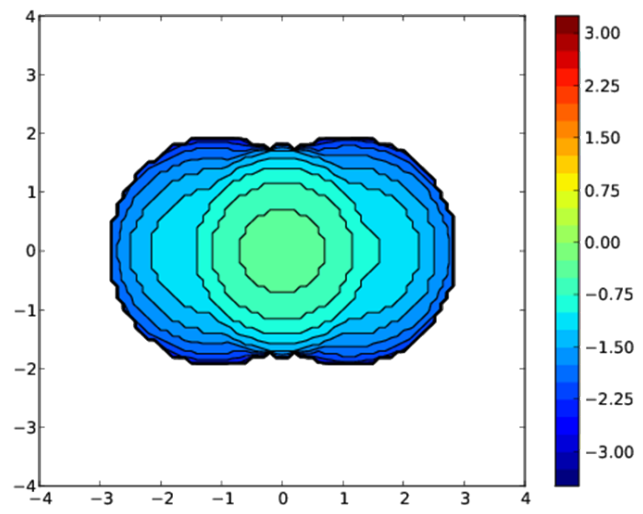

Figure 2: Steric maps for the NHC ligand of $3_{\mathrm{H}-\mathrm{H}}$, coordinated to iridium by a) carbene or b) nitrogen. The isocontour curves are given in $\AA$. The systems are oriented along the $z$-axis defined by the metal and the coordinating atom bonded to the metal. The two maps are computed with a radius of the sphere equal to $3.5 \AA$.

mation of a dinuclear complex. For $\mathbf{3}_{\mathbf{H}-\mathbf{T}}$ the $\%$ VBur is nearly identical, displaying values of 26.4 and 19.0 , for carbene and nitrogen coordination to the iridium centre, respectively.

Natural bond order (NBO) analysis on the iridium reveal that the two equivalent iridium centres in $\mathbf{3}_{\mathbf{H}-\mathbf{T}}$ display a charge on the metal of $0.009 e$, whereas -0.143 and $0.189 e$ for $\mathbf{3}_{\mathbf{H}-\mathbf{H}}$ for the iridium bonded to two carbene carbons and two nitrogen atoms of the NHC, respectively. This confirms that the metal-carbene coordination allocates more electron density on the metal than through the nitrogen.

Despite the dimeric nature of complex $\mathbf{3}$, hypothetically they might be discussed as aggregates of two monomeric moieties.
However the coupling between the two metal centres seems demonstrated by removing an electron of the system, thus the expected mixed valent $\operatorname{Ir}(\mathrm{I}) / \mathrm{Ir}$ (II) species turns out to display two identical metal centres that distribute equally the cost of the electrolysis of 3. Geometrically no asymmetry is observed, and together with the positive charge increase of $0.306 e$ on each former $\operatorname{Ir}(\mathrm{I})$ centre, shows that the effect on system 3 of the released electron is mainly paid by the metal centres, but also partially spread over the ligands [59].

To follow up the experimental results the tautomerism/metallotropism between pNHC and imidazole ligands in these iridium complexes bearing a doubly $\mathrm{C}, \mathrm{N}$-bridged dinuclear core was also computationally studied after the displacement of cod

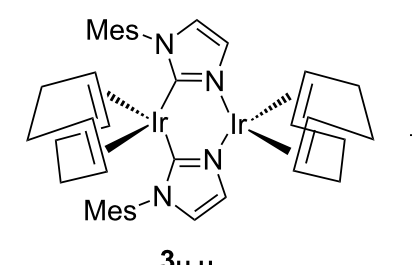

$3_{\mathrm{H}-\mathrm{H}}$

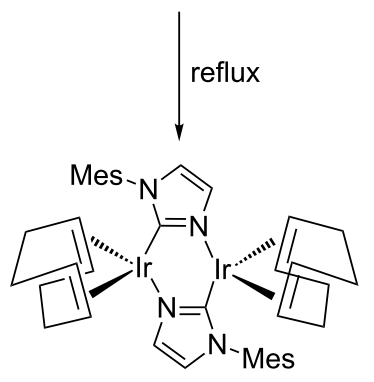

$3_{\mathrm{H}-\mathrm{T}}$<smiles>[O-][C+]1CCCC1</smiles>

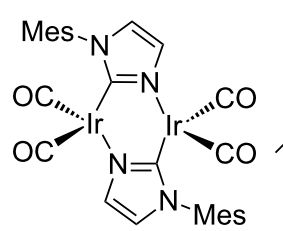

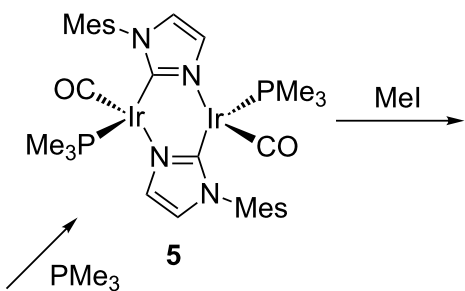

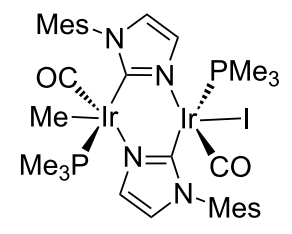

6 
ligands of $\mathbf{3}_{\mathbf{H}-\mathbf{H}}$ and $\mathbf{3}_{\mathbf{H}-\mathbf{T}}$ by CO in Scheme 3 [59], affording the tetracarbonyl complexes $\left[\mathrm{M}(\mathrm{CO})_{2}\left\{\mu-\mathrm{C}_{3} \mathrm{H}_{2} \mathrm{~N}_{2}\right.\right.$ (Mes)$\kappa \mathrm{C} 2, \kappa \mathrm{N} 3\}]_{2}, \mathbf{4}_{\mathbf{H}-\mathbf{H}}$ and $\mathbf{4}_{\mathbf{H}-\mathbf{T}}$, respectively. Next we evaluated the substitution of $\mathrm{CO}$ ligands by $\mathrm{PMe}_{3}$ affording complex $\left[\mathrm{M}(\mathrm{CO})\left(\mathrm{PMe}_{3}\right)\left\{\mu-\mathrm{C}_{3} \mathrm{H}_{2} \mathrm{~N}_{2} \text { (Mes) }-\kappa \mathrm{C} 2, \kappa \mathrm{N} 3\right\}\right]_{2}$ (5) and finally, oxidative addition of MeI to the latter complex $\mathbf{5}$ afforded the dinuclear complex $\left[\mathrm{M}(\mathrm{CO})_{2}\left(\mathrm{PMe}_{3}\right)_{2}(\mathrm{Me}) \mathrm{I}\left\{\mu-\mathrm{C}_{3} \mathrm{H}_{2} \mathrm{~N}_{2}\right.\right.$ (Mes)$\kappa \mathrm{C} 2, \kappa \mathrm{N} 3\}]_{2}$.

In agreement with experiments [59], without reflux conditions, the substitution of cod ligands by $\mathrm{CO}$ is extremely favored, being isomer $\mathbf{4}_{\mathbf{H}-\mathbf{T}} 48.5 \mathrm{kcal} / \mathrm{mol}$ more stable than $\mathbf{3}_{\mathbf{H}-\mathbf{T}}$, and again the equilibrium between $\mathbf{4}_{\mathbf{H}-\mathbf{H}}$ and $\mathbf{4}_{\mathbf{H}-\mathbf{T}}$ is displaced towards the latter species, by a difference of $3.0 \mathrm{kcal} / \mathrm{mol}$. Furthermore, the third CO ligand coordination on each iridium atom in $\mathbf{4}$ was faced but discarded due to a destabilization of 6.7 and $14.8 \mathrm{kcal} / \mathrm{mol}$ with respect to $\mathbf{4}_{\mathbf{H}-\mathbf{H}}$ and $\mathbf{4}_{\mathbf{H}-\mathbf{T}}$, respectively. Basically this lower stability is not only due to the sterical hindrance, but to the preferred quasi perfect square planar type of coordination on each iridium centre (see Figure 3). Going into electronic details, this $\mathbf{3} \rightarrow \mathbf{4}$ transformation also follows the principle of maximum hardness [70,71], i.e., the chemical hardness evolves from 39.6 to $46.7 \mathrm{kcal} / \mathrm{mol}$ bearing a H-T type of coordination. This increase of chemical hardness is a consequence of the increased stability of the HOMO, which results in a larger HOMO-LUMO gap $[61,65]$. To point out that the two types of coordination, $\mathrm{H}-\mathrm{H}$ and $\mathrm{H}-\mathrm{T}$, do not suppose a significant change of chemical hardness, just an increase for $\mathrm{H}-\mathrm{T}$ of only $0.6 \mathrm{kcal} / \mathrm{mol}$ for species 4 , whereas a decrease of 0.1 for species 3. Thus the electronics do not affect the equilibrium between both arrangements of the bridging ligands, but sterics as stated above. Further, the NBO charges show a decrease of the charge on both metals of $0.777 e$ in the $\mathbf{3} \rightarrow \mathbf{4}$ transformation. Despite the $\pi$-backdonation of CO the donation to the iridium centres is larger than the corresponding electron density transferred by the cod ligands in species 3 .

$\mathbf{4}_{\mathbf{H}-\mathbf{H}}$ and $\mathbf{4}_{\mathbf{H}-\mathbf{T}}$ evolves to complex $\mathbf{5}$, exchanging one $\mathrm{CO}$ by a $\mathrm{PMe}_{3}$ ligand on each iridium centre, releasing 5.0 and $2.0 \mathrm{kcal} / \mathrm{mol}$, respectively. Bearing an energy difference of $11.7 \mathrm{kcal} / \mathrm{mol}$ the $\mathrm{H}-\mathrm{T}$ isomer is favored with respect to the $\mathrm{H}-\mathrm{H}$, in agreement with experiments [59], because the $\mathrm{H}-\mathrm{H}$ coordination was not locate for $\mathbf{5}$, and further thermodynamics do not support the $\mathrm{H}-\mathrm{H}$ coordination for $\mathbf{5}$, with an energy endergonicity of $6.7 \mathrm{kcal} / \mathrm{mol}$ with respect the previous corresponding complex 4. Oxidative addition of MeI to 5 affords complex 6, in an exergonic release of $16.5 \mathrm{kcal} / \mathrm{mol}$, pointing out that there are several other isomers of complex 6 that differ from the Me and I coordination to each corresponding iridium centre. However all these alternative isomers of complex $\mathbf{6}$ are placed higher in energy by at least $12.9 \mathrm{kcal} / \mathrm{mol}$ (see Supporting Information File 1). The Ir-Ir distance in 6 is only $2.857 \AA$ (see Figure 4), which is a clear proof of concept of a formally metal-metal bonded $\mathrm{d}^{7}-\mathrm{d}^{7}$ complex, to be compared with complex 5, where this Ir-Ir distance elongates till 3.497 A. Furthermore, the MBO for the metal-metal bond reveals a significant value of 0.626 for complex 6 [72], being null for 5 and the previous complexes. Electronically, the charge on metals for complex 6 is 0.334 less charged, which is explained by, among other reasons, the weaker back-bonding from the metal to the CO ligands compared to $\mathbf{5}$, which affords the metal-metal interaction in 6. a)

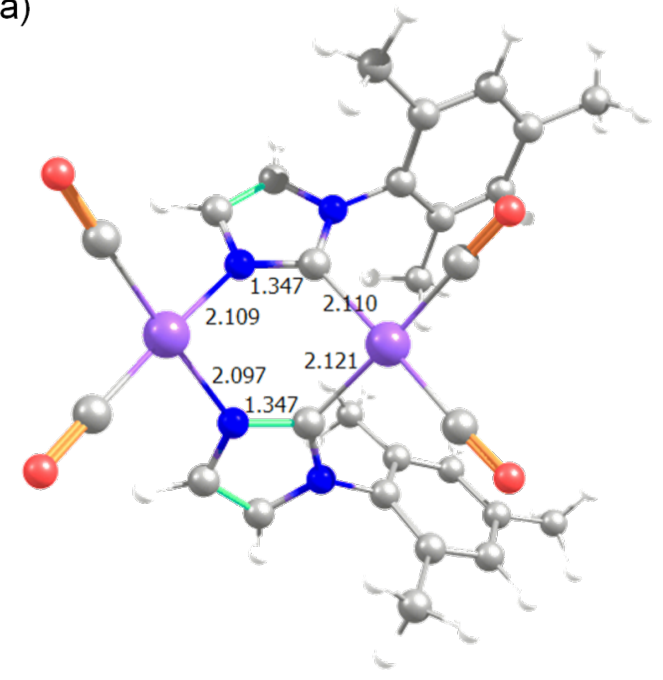

b)

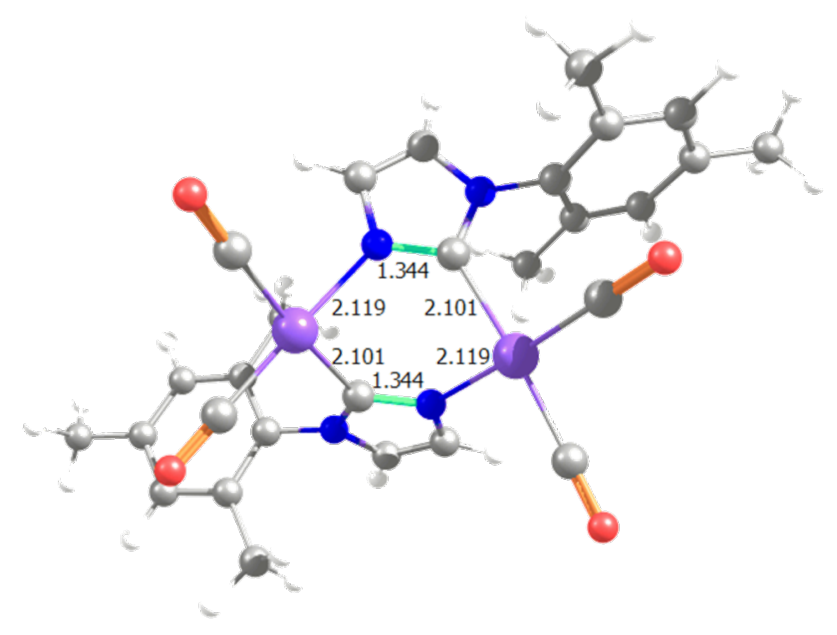

Figure 3: View of the molecular structure of a) $\mathbf{4}_{\mathrm{H}-\mathrm{H}}$ and b) $\mathbf{4}_{\mathrm{H}-\mathrm{T}}$ (main distances in $\AA$ ). 


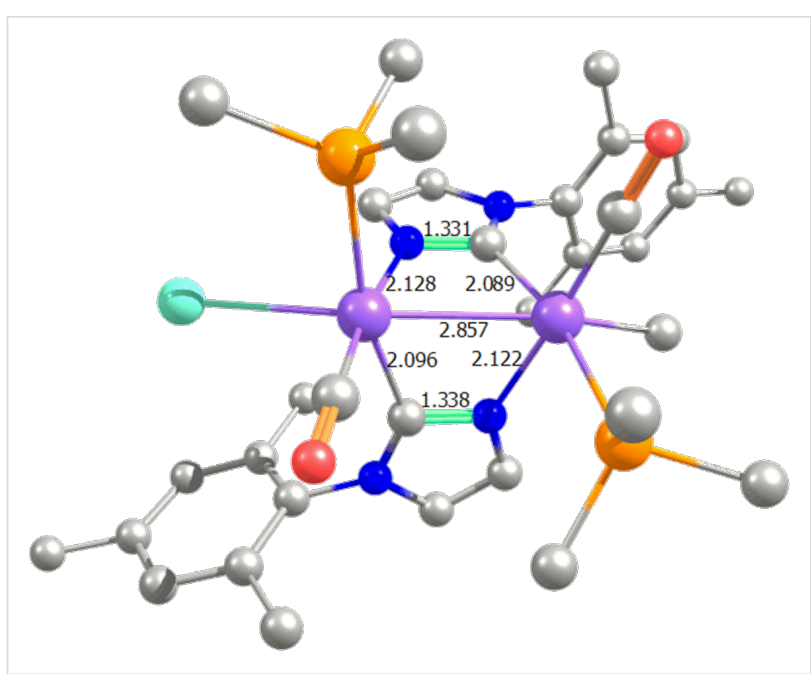

Figure 4: View of the molecular structure of 6 . Hydrogen atoms have been omitted for the sake of clarity (main distances in $\AA$ ).

To extent the scope of the reactivity of the NHC here, the cod ligands were first exchanged by ethylene, revealing a preferred H-T type of coordination of the NHC $(5.1 \mathrm{kcal} / \mathrm{mol})$. On the other hand, the iridium was replaced by rhodium to verify the innocent nature of the electronic properties of the metal, maintaining nearly completely the geometry features for complexes 3-6. Bearing rhodium complex $\mathbf{3}_{\mathbf{H}-\mathbf{T}}$ is again more stable than $\mathbf{3}_{\mathbf{H}-\mathbf{H}}$, even $0.2 \mathrm{kcal} / \mathrm{mol}$ more stable. To sum up, no change of behaviour between iridium and homologous rhodium complexes was observed. On the other hand, the evolution from H-T to $\mathrm{H}-\mathrm{H}$ arrangement was evaluated and mechanistically this process is predicted to be dissociative since neither intramolecular transition state was located nor the linear transits suggested energy barriers affordable at the experimental conditions.

\section{Conclusion}

The two possible $\mathrm{H}-\mathrm{T}$ and $\mathrm{H}-\mathrm{H}$ arrangements of a bridging NHC here have been studied in detail by DFT calculations. This is a contribution in the understanding of the thermodynamics of the subsequent $\mathrm{C}, \mathrm{N}$-bridged dinuclear iridium and rhodium complexes defined by Braunstein et al. [59] and the facility for the interconversion between these latter dimeric species. Steric maps confirm that the H-T is preferred since the metal centres are less sterically hindered, thus revealing the relatively unstable kinetic $\mathrm{H}-\mathrm{H}$ isomers with respect to the $\mathrm{H}-\mathrm{T}$ ones. However, screening the evolution from complex $\mathbf{3}$ to $\mathbf{6}$, going through complexes $\mathbf{4}$ and $\mathbf{5}$, the relative thermodynamics show a constant and sharp decay of energy, not due to steric factors, but mainly electronics.

\section{Computational Details}

The density functional calculations were performed on all the systems with the Gaussian 09 set of programs [73], Revision
D.01, at the BP86 GGA level [74-76], adding the Grimme D3 dispersion term [77]. For iridium and rhodium we used the small-core, quasi-relativistic Stuttgart/Dresden (SDD) effective core potential with an associated valence contracted basis set (standard SDD keywords in Gaussian 09) [78-80]. The electronic configuration of the molecular systems was described with the triple- $\zeta$ valence plus polarization (TZVP keyword in Gaussian) basis set on all main group atoms during geometry optimizations [81]. The reported energies have been obtained via single point calculations on the BP86 geometries with triple$\zeta$ valence plus polarization using the M06 functional [82]. Solvent effects, using either tetrahydrofuran, dichloromethane or toluene, were calculated with the polarizable continuous solvation model polarizable continuum model (PCM) model $[83,84]$, and non-electrostatic terms were also included. The cavity is created via a series of overlapping spheres. However, the numbers reported throughout the text here are based on THF because this is the solvent employed in the experiments bearing the H-H to H-T rearrangement [59]. The geometry optimizations were performed without symmetry constraints, and the nature of the extrema was checked by analytical frequency calculations. Furthermore, all the extrema were confirmed by calculation of the intrinsic reaction paths.

The reported free energies in this work include energies obtained at the M06/TZVP level of theory in solvent corrected with zero-point energies at $298.15 \mathrm{~K}$, together with the model of Martin et al. [85] which consists of thermal corrections and entropy effects evaluated at 1354 atm [86-89], with the BP86d3/TZVP method in the gas phase $[90,91]$.

\%VBur calculations: The buried volume calculations were performed with the SambVca package developed by Cavallo et al. [90]. The radius of the sphere around the metal centre was set to $3.5 \AA$, while for the atoms we adopted the Bondi radii scaled by 1.17 , and a mesh of $0.1 \AA$ was used to scan the sphere for buried voxels. The steric maps were evaluated with a development version of the SambVca package.

\section{Supporting Information}

\section{Supporting Information File 1}

Energies, cartesian coordinates, and 3D view for all DFT optimized species.

[http://www.beilstein-journals.org/bjoc/content/ supplementary/1860-5397-12-13-S1.pdf]

\section{Acknowledgements}

A.P. thanks the Spanish MINECO for a project CTQ201459832-JIN. 


\section{References}

1. Arduengo III, A. J.; Harlow, R. L.; Kline, M. J. Am. Chem. Soc. 1991, 113, 361-363. doi:10.1021/ja00001a054

2. Wanzlick, H.-W.; Kleiner, H.-J. Angew. Chem. 1961, 73, 493. doi:10.1002/ange.19610731408

3. Wanzlick, H.-W. Angew. Chem., Int. Ed. Engl. 1962, 1, 75-80. doi:10.1002/anie.196200751

4. Wanzlick, H.-W.; Schönherr, H.-J. Angew. Chem., Int. Ed. Engl. 1968, 7, 141-142. doi:10.1002/anie.196801412

5. Öfele, K. J. Organomet. Chem. 1968, 12, P42-P43. doi:10.1016/S0022-328X(00)88691-X

6. Öfele, K.; Herberhold, M. Angew. Chem., Int. Ed. Engl. 1970, 9, 739-740. doi:10.1002/anie.197007391

7. Jacobsen, H.; Correa, A.; Poater, A.; Costabile, C.; Cavallo, L. Coord. Chem. Rev. 2009, 253, 687-703. doi:10.1016/j.ccr.2008.06.006

8. Jacobsen, H.; Correa, A.; Poater, A.; Costabile, C.; Cavallo, L. Coord. Chem. Rev. 2009, 253, 2784. doi:10.1016/j.ccr.2009.04.007

9. Vougioukalakis, G.; Grubbs, R. H. Chem. Rev. 2010, 110, 1746-1787. doi:10.1021/cr9002424

10. Poater, A.; Cavallo, L. Beilstein J. Org. Chem. 2015, 11, 1767-1780. doi:10.3762/bjoc.11.192

11. Yuan, W.; Wei, Y.; Shi, M. ChemistryOpen 2013, 2, 63-68. doi:10.1002/open.201300002

12. Credendino, R.; Poater, A.; Ragone, F.; Cavallo, L. Catal. Sci. Technol. 2011, 1, 1287-1297. doi:10.1039/c1cy00052g

13. Vázquez-Serrano, L. D.; Owens, B. T.; Buriak, J. M. Chem. Commun. 2002, 2518-2519. doi:10.1039/b208403a

14. Lee, H. M.; Jiang, T.; Stevens, E. D.; Nolan, S. P. Organometallics 2001, 20, 1255-1258. doi:10.1021/om000990x

15. Grasa, G. A.; Viciu, M. S.; Huang, J.; Nolan, S. P. J. Org. Chem. 2001, 66, 7729-7737. doi:10.1021/jo010613+

16. Marion, N.; Navarro, O.; Mei, J.; Stevens, E. D.; Scott, N. M.; Nolan, S. P. J. Am. Chem. Soc. 2006, 128, 4101-4111. doi:10.1021/ja057704z

17. Vummaleti, S. V. C.; Talarico, G.; Nolan, S. P.; Cavallo, L.; Poater, A. Eur. J. Inorg. Chem. 2015, 4653-4657. doi:10.1002/ejic.201500905

18. Vummaleti, S. V. C.; Talarico, G.; Nolan, S. P.; Cavallo, L.; Poater, A. Org. Chem. Front. 2016, 3, 19-23. doi:10.1039/C5QO00281H

19. Dorel, R.; Echavarren, A. M. Chem. Rev. 2015, 115, 9028-9072. doi:10.1021/cr500691k

20. Nun, P.; Gaillard, S.; Poater, A.; Cavallo, L.; Nolan, S. P. Org. Biomol. Chem. 2011, 9, 101-104. doi:10.1039/C0OB00758G

21. Nun, P.; Dupuy, S.; Gaillard, S.; Poater, A.; Cavallo, L.; Nolan, S. P. Catal. Sci. Technol. 2011, 1, 58-61. doi:10.1039/c0cy00055h

22. Hoveyda, A. H.; Schrock, R. R. Chem. - Eur. J. 2001, 7, 945-950. doi:10.1002/1521-3765(20010302)7:5<945::AID-CHEM945>3.0.CO;23

23. Melaimi, M.; Soleilhavoup, M.; Bertrand, G. Angew. Chem., Int. Ed. 2010, 49, 8810-8849. doi:10.1002/anie.201000165

24. Bourissou, D.; Guerret, O.; Gabbaï, F. P.; Bertrand, G. Chem. Rev. 2000, 100, 39-92. doi:10.1021/cr940472u

25. de Frémont, P.; Marion, N.; Nolan, S. P. Coord. Chem. Rev. 2009, 253, 862-892. doi:10.1016/j.ccr.2008.05.018

26. Hahn, F. E.; Jahnke, M. C. Angew. Chem., Int. Ed. 2008, 47, 3122-3172. doi:10.1002/anie.200703883

27. Kuwata, S.; Ikariya, T. Chem. - Eur. J. 2011, 17, 3542-3556. doi:10.1002/chem.201003296

28. Kuwata, S.; Ikariya, T. Chem. Commun. 2014, 50, 14290-14300. doi:10.1039/C4CC04457F
29. Hahn, F. E. ChemCatChem 2013, 5, 419-430. doi:10.1002/cctc. 201200567

30. Hsieh, C.-H.; Pulukkody, R.; Darensbourg, M. Y. Chem. Commun. 2013, 49, 9326-9328. doi:10.1039/c3cc45091k

31. Brackemeyer, D.; Hervé, A.; Schulte to Brinke, C.; Jahnke, M. C.; Hahn, F. E. J. Am. Chem. Soc. 2014, 136, 7841-7844. doi:10.1021/ja5030904

32. Hahn, F. E.; Langenhahn, V.; Lügger, T.; Pape, T.; Le Van, D. Angew. Chem., Int. Ed. 2005, 44, 3759-3763. doi:10.1002/anie.200462690

33. Kösterke, T.; Pape, T.; Hahn, F. E. J. Am. Chem. Soc. 2011, 133, 2112-2115. doi:10.1021/ja110634h

34. Dobereiner, G. E.; Chamberlin, C. A.; Schley, N. D.; Crabtree, R. H. Organometallics 2010, 29, 5728-5731. doi:10.1021/om100452g

35. Kösterke, T.; Kösters, J.; Würthwein, E.-U.; Mück-Lichtenfeld, C.; Schulte to Brinke, C.; Lahoz, F.; Hahn, F. E. Chem. - Eur. J. 2012, 18, 14594-14598. doi:10.1002/chem.201202973

36. Kunz, P. C.; Wetzel, C.; Kögel, S.; Kassack, M. U.; Spingler, B. Dalton Trans. 2011, 40, 35-37. doi:10.1039/C0DT01089H

37. Das, R.; Hepp, A.; Daniliuc, C. G.; Hahn, F. E. Organometallics 2014, 33, 6975-6987. doi:10.1021/om501120u

38. Das, R.; Daniliuc, C. G.; Hahn, F. E. Angew. Chem., Int. Ed. 2014, 53, 1163-1166. doi:10.1002/anie.201308269

39. Hahn, F. E.; Langenhahn, V.; Pape, T. Chem. Commun. 2005, 5390-5392. doi:10.1039/b510996e

40. Ruiz, J.; García, G.; Mosquera, M. E. G.; Perandones, B. F.; Gonzalo, M. P.; Vivanco, M. J. Am. Chem. Soc. 2005, 127, 8584-8585. doi:10.1021/ja042879e

41. He, F.; Braunstein, P.; Wesolek, M.; Danopoulos, A. A. Chem. Commun. 2015, 51, 2814-2817. doi:10.1039/C4CC10109J

42. Hill, C.; Bosold, F.; Harms, K.; Lohrenz, J. C. W.; Marsch, M.; Schmieczek, M.; Boche, G. Chem. Ber./Recl. 1997, 130, 1201-1212. doi:10.1002/cber.19971300907

43. Hilf, C.; Bosold, F.; Harms, K.; Marsch, M.; Boche, G. Chem. Ber./Recl. 1997, 130, 1213-1221. doi:10.1002/cber.19971300908

44. Marchenko, A. P.; Koidan, H. N.; Pervak, I. I.; Huryeva, A. N.; Zarudnitskii, E. V.; Tolmachev, A. A.; Kostyuk, A. N. Tetrahedron Lett. 2012, 53, 494-496. doi:10.1016/j.tetlet.2011.11.054

45. Beveridge, K. A.; Bushnell, G. W.; Stobart, S. R.; Atwood, J. L.; Zaworotko, M. J. Organometallics 1983, 2, 1447-1451. doi:10.1021/om50004a035

46. Bushnell, G. W.; Fjeldsted, D. O. K.; Stobart, S. R.; Zaworotko, M. J.; Knox, S. A. R.; MacPherson, K. A. Organometallics 1985, 4, 1107-1114. doi:10.1021/om00125a029

47. Brost, R. D.; Stobart, S. R. Inorg. Chem. 1989, 28, 4307-4308. doi:10.1021/ic00323a001

48. Brost, R. D.; Fjeldsted, D. O. K.; Stobart, S. R. J. Chem. Soc., Chem. Commun. 1989, 488-490. doi:10.1039/c39890000488

49. Lichtenberger, D. L.; Copenhaver, A. S.; Gray, H. B.; Marshall, J. L.; Hopkins, M. D. Inorg. Chem. 1988, 27, 4488-4493. doi:10.1021/ic00297a030

50. Bonati, F.; Oro, L. A.; Pinillos, M. T.; Tejel, C.; Bovio, B. J. Organomet. Chem. 1994, 465, 267-274. doi:10.1016/0022-328X(94)87065-9

51. Yuan, Y.; Jiménez, M. V.; Sola, E.; Lahoz, F. J.; Oro, L. A. J. Am. Chem. Soc. 2002, 124, 752-753. doi:10.1021/ja016753i

52. Bushnell, G. W.; Fjeldsted, D. O. K.; Stobart, S. R.; Zaworotko, M. J. J. Chem. Soc., Chem. Commun. 1983, 580-581. doi:10.1039/c39830000580 
53. Atwood, J. L.; Beveridge, K. A.; Bushnell, G. W.; Dixon, K. R.; Eadie, D. T.; Stobart, S. R.; Zaworotko, M. J. Inorg. Chem. 1984, 23, 4050-4057. doi:10.1021/ic00192a042

54. Bushnell, G. W.; Fjeldsted, D. O. K.; Stobart, S. R.; Wang, J. Organometallics 1996, 15, 3785-3787. doi:10.1021/om9601864

55. Coleman, A. W.; Eadie, D. T.; Stobart, S. R.; Zaworotko, M. J.; Atwood, J. L. J. Am. Chem. Soc. 1982, 104, 922-923. doi:10.1021/ja00367a076

56. Bushnell, G. W.; Decker, M. J.; Eadie, D. T.; Stobart, S. R.; Vefghi, R.; Atwood, J. L.; Zaworotko, M. J. Organometallics 1985, 4, 2106-2111. doi:10.1021/om00131a007

57. Fjeldsted, D. O. K.; Stobart, S. R.; Zaworotko, M. J. J. Am. Chem. Soc. 1985, 107, 8258-8259. doi:10.1021/ja00312a074

58. Arthurs, M. A.; Bickerton, J.; Stobart, S. R.; Wang, J. Organometallics 1998, 17, 2743-2750. doi:10.1021/om970554j

59. He, F.; Ruhlmann, L.; Gisselbrecht, J.-P.; Choua, S.; Orio, M.; Wesolek, M.; Danopoulos, A. A.; Braunstein, P. Dalton Trans. 2015, 44, 17030-17044. doi:10.1039/C5DT02403J

60. Root-mean-square deviation ( $\mathrm{rmsd}$ ) is calculated for distances and angles: $\mathrm{s}_{\mathrm{n}-1}=\left[\sum_{\mathrm{i}=1 \rightarrow \mathrm{N}}(\mathrm{CV}-\mathrm{EV})^{2} /(\mathrm{N}-1)\right]^{1 / 2}$, where $\mathrm{CV}$ means calculated value, EV means experimental value ( $X$-ray data), and $N$ is the number of distances or angles taken into account.

61. Costas, M.; Ribas, X.; Poater, A.; López Balvuena, J. M.; Xifra, R.; Company, A.; Duran, M.; Solà, M.; Llobet, A.; Corbella, M.; Usón, M. A.; Mahía, J.; Solans, X.; Shan, X.; Benet-Buchholz, J. Inorg. Chem. 2006, 45, 3569-3581. doi:10.1021/ic051800j

62. Mola, J.; Rodríguez, M.; Romero, I.; Llobet, A.; Parella, T.; Poater, A.; Duran, M.; Solà, M.; Benet-Buchholz, J. Inorg. Chem. 2006, 45, 10520-10529. doi:10.1021/ic061126I

63. Mayer, I. Int. J. Quantum Chem. 1984, 26, 151-154. doi:10.1002/qua.560260111

64. Poater, A.; Ragone, F.; Correa, A.; Cavallo, L. J. Am. Chem. Soc. 2009, 131, 9000-9006. doi:10.1021/ja902552m

65. Poater, A. J. Phys. Chem. A 2009, 31, 9030-9040. doi:10.1021/jp9040716

66. Poater, A.; Cosenza, B.; Correa, A.; Giudice, S.; Ragone, F.; Scarano, V.; Cavallo, L. Eur. J. Inorg. Chem. 2009, 1759-1766. doi:10.1002/ejic. 200801160

67. Bosson, J.; Poater, A.; Cavallo, L.; Nolan, S. P. J. Am. Chem. Soc. 2010, 132, 13146-13149. doi:10.1021/ja104961s

68. Poater, A.; Ragone, F.; Mariz, R.; Dorta, R.; Cavallo, L. Chem. - Eur. J. 2010, 16, 14348-14353. doi:10.1002/chem.201001938

69. Giovanni, C.; Poater, A.; Benet-Buchholz, J.; Cavallo, L.; Solà, M.; Llobet, A. Chem. - Eur. J. 2014, 20, 3898-3902. doi:10.1002/chem.201304699

70. Parr, R. G.; Donnelly, R. A.; Levy, M.; Palke, W. E. J. Chem. Phys. 1978, 68, 3801-3807. doi:10.1063/1.436185

71. Parr, R. G.; Pearson, R. G. J. Am. Chem. Soc. 1983, 105, 7512-7516. doi:10.1021/ja00364a005

72. Poater, A.; Moradell, S.; Pinilla, E.; Poater, J.; Solà, M.; Martínez, M. A.; Llobet, A. Dalton Trans. 2006, 1188-1196. doi:10.1039/B511625M

73. Gaussian 09, Revision D.01; Gaussian, Inc.: Wallingford, CT, 2009.

74. Becke, A. D. Phys. Rev. A 1988, 38, 3098-3100. doi:10.1103/PhysRevA.38.3098

75. Perdew, J. P. Phys. Rev. B 1986, 33, 8822-8824. doi:10.1103/PhysRevB.33.8822

76. Perdew, J. P. Phys. Rev. B 1986, 34, 7406. doi:10.1103/PhysRevB.34.7406
77. Grimme, S.; Antony, J.; Ehrlich, S.; Krieg, H. J. Chem. Phys. 2010, 132, 154104. doi:10.1063/1.3382344

78. Häussermann, U.; Dolg, M.; Stoll, H.; Preuss, H.; Schwerdtfeger, P.; Pitzer, R. M. Mol. Phys. 1993, 78, 1211-1224. doi:10.1080/00268979300100801

79. Küchle, W.; Dolg, M.; Stoll, H.; Preuss, H. J. Chem. Phys. 1994, 100, 7535-7542. doi:10.1063/1.466847

80. Leininger, T.; Nicklass, A.; Stoll, H.; Dolg, M.; Schwerdtfeger, P. J. Chem. Phys. 1996, 105, 1052-1059. doi:10.1063/1.471950

81. Schäfer, A.; Horn, H.; Ahlrichs, R. J. Chem. Phys. 1992, 97, 2571-2577. doi:10.1063/1.463096

82. Zhao, Y.; Truhlar, D. G. Theor. Chem. Acc. 2008, 120, 215-241. doi:10.1007/s00214-007-0310-x

83. Barone, V.; Cossi, M. J. Phys. Chem. A 1998, 102, 1995-2001. doi:10.1021/jp9716997

84. Tomasi, J.; Persico, M. Chem. Rev. 1994, 94, 2027-2094. doi:10.1021/cr00031a013

85. Martin, R. L.; Hay, P. J.; Pratt, L. R. J. Phys. Chem. A 1998, 102, 3565-3573. doi:10.1021/jp980229p

86. Poater, A.; Pump, E.; Vummaleti, S. V. C.; Cavallo, L. J. Chem. Theory Comput. 2014, 10, 4442-4448. doi: $10.1021 /$ ct5003863

87. Pump, E.; Slugovc, C.; Cavallo, L.; Poater, A. Organometallics 2015, 34, 3107-3111. doi:10.1021/om501246q

88. Urbina-Blanco, C. A.; Poater, A.; Lebl, T.; Manzini, S.; Slawin, A. M. Z.; Cavallo, L.; Nolan, S. P. J. Am. Chem. Soc. 2013, 135, 7073-7079. doi:10.1021/ja402700p

89. Manzini, S.; Poater, A.; Nelson, D. J.; Cavallo, L.; Slawin, A. M. Z.; Nolan, S. P. Angew. Chem., Int. Ed. 2014, 53, 8995-8999. doi:10.1002/anie.201403770

90. Manzini, S.; Poater, A.; Nelson, D. J.; Cavallo, L.; Nolan, S. P. Chem. Sci. 2014, 5, 180-188. doi:10.1039/C3SC52612G

91. García-Melchor, M.; Pacheco, M. C.; Nájera, C.; Lledós, A.; Ujaque, G. ACS Catal. 2012, 2, 135-144. doi:10.1021/cs200526x

\section{License and Terms}

This is an Open Access article under the terms of the Creative Commons Attribution License (http://creativecommons.org/licenses/by/2.0), which permits unrestricted use, distribution, and reproduction in any medium, provided the original work is properly cited.

The license is subject to the Beilstein Journal of Organic Chemistry terms and conditions:

(http://www.beilstein-journals.org/bjoc)

The definitive version of this article is the electronic one which can be found at: $\underline{\text { doi: } 10.3762 / \text { bjoc. } 12.13}$ 